\title{
Reduced activity of 11 $\beta$-hydroxysteroid dehydrogenase in patients with cholestasis
}

\author{
Cristiana Quattropani, Bruno Vogt, Alex Odermatt, Bernhard Dick, Brigitte M. Frey, \\ and Felix J. Frey
}

University Hospital of Berne, Berne, Switzerland

Address correspondence to: Felix J. Frey, Division of Nephrology and Hypertension, Inselspital, University of Berne, Freiburgstrasse 10, 3010 Berne, Switzerland. Phone: 4131-632-9629; Fax: 4131-632-9734; E-mail: felix.frey@insel.ch.

Cristiana Quattropani and Bruno Vogt contributed equally to this work.

Received for publication March 15, 2001, and accepted in revised form September 10, 2001.

\begin{abstract}
Enhanced renal sodium retention and potassium loss in patients with cirrhosis is due to activation of mineralocorticoid receptors (MRs). Increased aldosterone concentrations, however, do not entirely explain the activation of MR in cirrhosis. Here, we hypothesize that cortisol activates MRs in patients with cholestasis. We present evidence that access of cortisol to MRs is a result of bile acidmediated inhibition of $11 \beta$-hydroxysteroid dehydrogenase type 2 (11ß-HSD2), an MR-protecting enzyme that converts cortisol to cortisone. Twelve patients with biliary obstruction and high plasma bile acid levels were studied before and after removal of the obstruction. The urinary ratio of (tetrahydrocortisol $+5 \alpha$-tetrahydrocortisol)/tetrahydrocortisone, a measure of $11 \beta$-HSD2 activity, decreased from a median of 1.91 during biliary obstruction to 0.78 at 4 and 8 weeks after removal of the obstruction and normalization of plasma bile acid concentrations. In order to demonstrate that bile acids facilitate access of cortisol to the MR by inhibiting 11 $\beta$-HSD2, an MR translocation assay was performed in HEK-293 cells transfected with human 11 $\beta$-HSD2 and tagged MR. Increasing concentrations of chenodeoxycholic acid led to cortisol-induced nuclear translocation of MR. In conclusion, $11 \beta$-HSD2 activity is reduced in cholestasis, which results in MR activation by cortisol.
\end{abstract}

J. Clin. Invest. 108:1299-1305 (2001). DOI:10.1172/JCI200112745.

\section{Introduction}

The intracellular access of glucocorticoids to mineraloor glucocorticoid receptors is modulated by the $11 \beta$ hydroxysteroid dehydrogenase (11 $\beta$-HSD) enzymes, which interconvert biologically active $11 \beta$-hydroxyglucocorticoids and inactive 11-ketosteroids (1-4) (Figure $1)$. The type 2 isoform, $11 \beta$-HSD2, catalyzes the dehydrogenation of $11 \beta$-hydroxyglucocorticoids, has a nanomolar $K_{\mathrm{m}}$ for glucocorticoids, utilizes $\mathrm{NAD}^{+}$as a cofactor, and is localized in the membrane of the endoplasmic reticulum with a cytoplasmic orientation of its catalytic domain $(5,6)$. The enzyme exhibits cell-specific constitutive expression in mineralocorticoid target tissues, such as epithelial cells from the colon and renal cortical collecting tubule $(5,7)$, where its primary function is to protect the mineralocorticoid receptor (MR) from promiscuous activation by $11 \beta$-hydroxyglucocorticoids $(1,2,8,9)$. Such protection is necessary because the glucocorticoid cortisol circulates in a 100 -fold molar excess to aldosterone in vivo and binds to MR with an affinity similar to the physiological mineralocorticoid aldosterone $(1,2,10)$. Loss-of-function mutation or inhibition of $11 \beta$-HSD2 allows glucocorticoids including cortisol to promote renal sodium retention and potassium excretion in the cortical collecting tubule $(1,2,9,11,12)$.

Renal sodium retention and potassium loss are observed in patients suffering from liver cirrhosis. Tra- ditionally, this abnormality is attributed to secondary hyperaldosteronism as a consequence of renal hypoperfusion related to intra-abdominal fluid sequestration (13). This concept has been questioned due to the observation that renal sodium retention precedes formation of ascites in some situations (14-16). Furthermore, it is unclear whether the amount of sodium retention and potassium excretion is completely explained by the increased aldosterone concentrations in patients with cirrhosis (13-18). Thus, other mechanisms contributing to renal sodium retention should be considered. We hypothesize that cortisol-induced activation of MR as a consequence of reduced activity of $11 \beta-H S D 2$ is such a candidate mechanism. This hypothesis is supported by the following observations. First, bile acids inhibit 11ß-HSD2 in a concentrationdependent manner in transfected COS- 1 cells and renal microsomes or isolated cortical collecting tubules from rats (19-21). Second, liver cirrhosis induced by bile duct ligation reduced the activity of $11 \beta-H S D 2$ and the corresponding mRNA levels assessed in renal tissue. In addition, the urinary ratio of (tetrahydrocorticosterone $+5 \beta$-tetrahydrocorticosterone)/11-dehydro-tetrahydrocorticosterone, an in vivo measure of $11 \beta$-HSD2 activity in rats, is increased (19). Third, blood pressure increases in rats treated with chenodeoxycholic acid (CDCA) (22); and fourth, adrenalectomized rats pretreated with CDCA, but not with cholic acid (CA), 

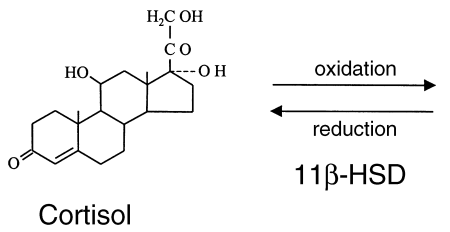

$11 \beta-H S D$

\section{Figure 1}

Cortisol/cortisone shuttle. Cortisol is biologically active because it can bind to gluco- and mineralocorticoid receptors. The corresponding 11 -keto-steroid cortisone is unable to do so. The $11 \beta$-hydroxysteroid dehydrogenase enzymes (11 $\beta$-HSD) account for the interconversion of cortisol and cortisone and, thus, regulate local intracellular access of glucocorticoids to the receptors.

show enhanced renal sodium retention and urinary potassium excretion (23). In this report, we present data indicating that $11 \beta$-HSD2 activity is reduced in patients with cholestasis and provide evidence for cortisol-induced activation of MR by CDCA.

\section{Methods}

Patients. We prospectively studied 12 patients (eight women and four men) with a median age of 64 years (range 18-92 years) with obstructive jaundice referred to our institution for diagnostic or therapeutic endoscopic retrograde cholangio-pancreaticography (ERCP) (Tables 1 and 2). The inclusion criterion was obstructive jaundice with serum bilirubin greater than 100 $\mu \mathrm{mol} / \mathrm{l}$ (four times the upper range). The underlying disease states are given in Table 2. Neither patient with neoplastic disease had evidence of metastasis. Stones were detected in the common bile duct of nine patients; these stones were extracted and papillotomy was performed. In the patient with a tumor of the head of the pancreas, the obstruction was treated by endoscopic stenting, and the two other patients underwent surgical removal of the biliary obstruction.

No patient was being treated with ramipril or captopril, two ACE inhibitors shown to increase renal $11 \beta$-HSD activity in rats (24) (Table 2). One patient was receiving furosemide $(40 \mathrm{mg} /$ day), a diuretic known to inhibit human $11 \beta$-HSD2 activity (1). These patients were given the same doses of ACE inhibitors and furosemide before and after the removal of the biliary obstruction. Biochemical tests were performed at admission before ERCP and twice thereafter, with a first review at a median of 41 days (range 20-63 days) and a second review at a median of 91 days (range 60-143 days). At the second review two patients were not available for investigation.

Analysis of urinary steroid metabolites by gas chromatography-mass spectrometry. Urine sample preparation consisted of pre-extraction, enzymatic hydrolysis, extraction from the hydrolysis mixture, derivatization, and gel filtration $(25,26)$. The recovery standard was prepared by adding $2.5 \mu \mathrm{g}$ of medroxyprogesterone to 1.5 $\mathrm{ml}$ of urine. The sample was extracted on a Sep-Pak C18 column (Waters Corp., Milford, Massachusetts,
USA), dried, reconstituted in $0.1 \mathrm{M}$ acetate buffer, $\mathrm{pH}$ 4.6, and hydrolyzed with powdered Helix pomatia enzyme (12.5 mg; Sigma Chemical Co., St. Louis, Missouri, USA) and $12.5 \mu \mathrm{l}$ of $\beta$-glucuronidase/arylsulfatase liquid enzyme (Roche Diagnostics, Rotkreuz, Switzerland). The resulting free steroids were extracted on a Sep-Pak C18 cartridge. The mixture of internal standards $(2.5 \mu \mathrm{g}$ each of $5 \alpha$-androstane- $3 \alpha, 17 \alpha$-diol, stigmasterol, and cholesteryl butyrate, and $0.15 \mu \mathrm{g}$ of $3 \beta 5 \beta$-tetrahydroaldosterone) was added to this extract and the sample derivatized to form the methyloximetrimethylsilyl ethers. Analyses were performed on a Hewlett-Packard gas chromatograph 6890 (Hewlett Packard, Palo Alto, California, USA) with a mass selective detector 5973 by selective ion monitoring (SIM). One characteristic ion was chosen for each compound being measured. The derivatized samples were analyzed during a temperature-programmed run $\left(210-265^{\circ} \mathrm{C}\right)$ over a 35 -minute period. A steroid mixture containing a known amount of all steroid metabolites to be measured was analyzed on a regular basis to act as a calibration standard (including regular updating of responses and retention times). In each case the ion-peak was quantified against that of the stigmasterol internal standard. Using this method the following metabolites were determined in urine: cortisol $(\mathrm{F})$, cortisone $(\mathrm{E})$, tetrahydrocortisol (THF), 5-allo-tetrahydrocortisol (5 $\alpha \mathrm{THF})$, and tetrahydrocortisone (THE).

Analysis of bile acids by gas chromatography-mass spectrometry in urine. Each sample was analyzed twice, once with solvolysis to yield total (sulfated and unsulphated) bile acids and once without solvolysis for unsulphated bile acids (27). After addition of $4 \mu \mathrm{g}$ of 23 -nordeoxycholic acid as a recovery standard to $1.5 \mathrm{ml}$ of urine, total bile acids were extracted on a Sep-Pak C18 cartridge. Solvolysis was performed at $50^{\circ} \mathrm{C}$ for 1 hour using $5 \mathrm{ml}$ of tetrahydrofuran containing $5 \mu \mathrm{l}$ of $4 \mathrm{M}$ sulfuric acid. Solvolyzed samples were neutralized with ethanolic $4 \mathrm{M} \mathrm{NaOH}$ prior to enzymatic hydrolysis. Both samples (solvolyzed and unsolvolyzed) were then subjected to enzymatic hydrolysis with cholylglycine hydrolase in $0.1 \mathrm{M}$ phosphate buffer, $\mathrm{pH} 5.6,55^{\circ} \mathrm{C}$ for 4 hours for deconjugate glycine and taurine conjugates and with $\beta$-glucuronidase in $0.1 \mathrm{M}$ acetate buffer, $\mathrm{pH}$ $4.6,55^{\circ} \mathrm{C}$ for 3 hours for deconjugate glucuronic acid conjugates. After each hydrolysis sample was extracted on Sep-Pak C18 columns, $4 \mu \mathrm{g}$ of $5 \beta$-cholestan-3 $\beta$-ol were added as standard for derivatization and gas chromatography. Samples were then derivatized to form the methylester-trimethylsilyl ethers. Methylation was performed using ethereal diazomethane (freshly prepared in a Wheaton generator; Aldrich Chemical Co., Milwaukee, Wisconsin, USA). Bile acid extracts were dissolved in $100 \mu \mathrm{l}$ of methanol, and $0.3 \mathrm{ml}$ of ethereal diazomethane was added. The reaction was carried out at room temperature for 30 minutes. After evaporation of the ether the samples were silylated with $100 \mu \mathrm{l}$ of trimethylsilyl imidazole at $60^{\circ} \mathrm{C}$ for 1 hour. The derivatives were purified by gel filtration on Lipidex-5000 
Table 1

Biochemical parameters with and without cholestasis in 12 patients

\begin{tabular}{|c|c|c|c|c|c|}
\hline \multirow[t]{2}{*}{ Parameter } & \multirow{2}{*}{$\begin{array}{c}\text { Cholestasis } \\
\text { median (range) }\end{array}$} & \multirow{2}{*}{$\begin{array}{c}\text { First review } \\
\text { median (range) }\end{array}$} & \multirow{2}{*}{$\begin{array}{l}\text { Second review } \\
\text { median (range) }\end{array}$} & \multicolumn{2}{|c|}{$P$ value } \\
\hline & & & & $\begin{array}{l}\text { Cholestasis vs. } \\
\text { first review }\end{array}$ & $\begin{array}{l}\text { Cholestasis vs. } \\
\text { second review }\end{array}$ \\
\hline$(\mathrm{THF}+5 \alpha \mathrm{THF}) / \mathrm{THE}^{\mathrm{A}}$ & $1.91(0.76-4.26)$ & $0.78(0.50-1.65)$ & $0.78(0.34-1.19)$ & $<0.005$ & $<0.002$ \\
\hline Bile acids $(\mu \mathrm{mol} / \mathrm{l})^{\mathrm{B}}$ & $64.6(3.25-99)$ & $1.6(0.40-8.1)$ & $1.9(0.31-10.1)$ & $<0.0001$ & $<0.0001$ \\
\hline Bilirubin $(\mu \mathrm{mol} / \mathrm{l})^{B}$ & $140(105-305)$ & $10(6-21)$ & $7(4-23)$ & $<0.0001$ & $<0.0001$ \\
\hline $\operatorname{ALT}(\mathrm{U} / \mathrm{I})^{\mathrm{B}}$ & $246(33-642)$ & $25(10-64)$ & $21(10-47)$ & $<0.01$ & $<0.005$ \\
\hline Alkaline phosphatase $(\mathrm{U} / \mathrm{I})^{\mathrm{B}}$ & $307(123-863)$ & $107(67-267)$ & $105(61-239)$ & $<0.02$ & $<0.01$ \\
\hline$\gamma$-GT $(U / I)^{B}$ & $416(25-899)$ & $57(35-136)$ & $32(11-86)$ & $<0.02$ & $<0.001$ \\
\hline
\end{tabular}

ALT, alanine aminotransferase; $\gamma$-GT, $\gamma$-glutamyl transpeptidase. ${ }^{A}$ Analysis performed in urine; ${ }^{B}$ analysis performed in plasma.

columns generator (Packard Bioscience S.A., Zürich, Switzerland) to remove the excess silylating agent.

Analysis was performed by gas chromatographymass spectrometry using a Hewlett-Packard gas chromatograph 6890 equipped with a mass selective detector 5973 by SIM. One characteristic ion was programmed for each bile acid being analyzed. The samples were chromatographed during a temperatureprogrammed run $\left(210-265^{\circ} \mathrm{C}\right)$ over 30 minutes. Calibration lines were established over the range of $20-40,000 \mathrm{ng} / \mathrm{ml}$ (correlation coefficients > 0.99). A control urine sample was analyzed in each series to check the accuracy of the method. Coefficients of variation for intra- and interday analysis were below $20 \%$.

Chenodeoxycholic (m/z 370) and cholic (m/z 458) acid were quantified (ion number monitored in parentheses) together with 23-nor-deoxycholic acid (m/z 521, recovery standard) and $5 \beta$-cholestan-3 $\beta$-ol $(\mathrm{m} / \mathrm{z} 370$, derivatization and gas chromatography standard).

Assessment of liver parameters and renal function. Cholestasis was assessed by means of bilirubin, alkaline phosphatase, $\gamma$-glutamyl-transpeptidase, and bile acids in plasma. Bile acids were measured by radioimmunoassay (RIA) (Becton Dickinson Co., Orangeburg, New York, USA). Creatinine, potassium, and sodium levels were determined in serum and urine.

$M R$ translocation assay. In order to demonstrate that bile acids facilitate access of cortisol to the MR by inhibiting $11 \beta$-HSD2, FLAG epitope-tagged human $11 \beta$-HSD2 and hemagglutinin (HA) epitope-tagged human MR were coexpressed in HEK-293 cells.

Expression constructs. The FLAG-tagged human $11 \beta$-HSD2 expression plasmid and the HA-tagged human MR expression plasmid were constructed as described previously $(6,8)$. Both tagged $11 \beta$-HSD2 and tagged MR were functionally indistinguishable from their wild-type proteins.

Transfection and cell culture. HEK-293 cells were grown on glass cover slips in six-well plates containing $2 \mathrm{ml}$ of DMEM medium supplemented with $10 \%$ FCS. Cells were cotransfected with $0.5 \mu \mathrm{g}$ of FLAG-tagged $11 \beta$ HSD 2 and $0.5 \mu \mathrm{g}$ of HA-tagged MR. Six hours later the cells were washed twice with charcoal-treated medium followed by incubation of cells for a further 14 hours. The absence of glucocorticoids from the charcoal-treated medium was verified by gas chromatography-mass spectrometry. Various concentrations of CDCA and 10 nM cortisol were added 20 hours after transfection, and cells were incubated for 45 minutes at $37^{\circ} \mathrm{C}$.

Immunostaining and fluorescence microscopy. After 45 minutes of incubation with cortisol and CDCA, cells were washed once with prewarmed NAPS buffer (100 mM sodium phosphate, $\mathrm{pH} 7.4,120 \mathrm{mM}$ sucrose) followed by fixation for 10 minutes with $4 \%$ paraformaldehyde in NAPS buffer. Cells were immunolabeled as described $(6,8)$ by using mouse monoclonal anti-FLAG antibody M2 (Sigma Chemical Co.) and ALEXA-488 anti-mouse antibody (Molecular Probes Inc., Eugene, Oregon, USA) for detection of FLAG-tagged 11 $\beta$-HSD2 and rat monoclonal anti-HA antibody (Roche Diagnostics) and ALEXA-594 anti-rat antibody (Molecular Probes Inc.) for detection of HA-tagged MR. Samples were analyzed by confocal microscopy. For quantitative
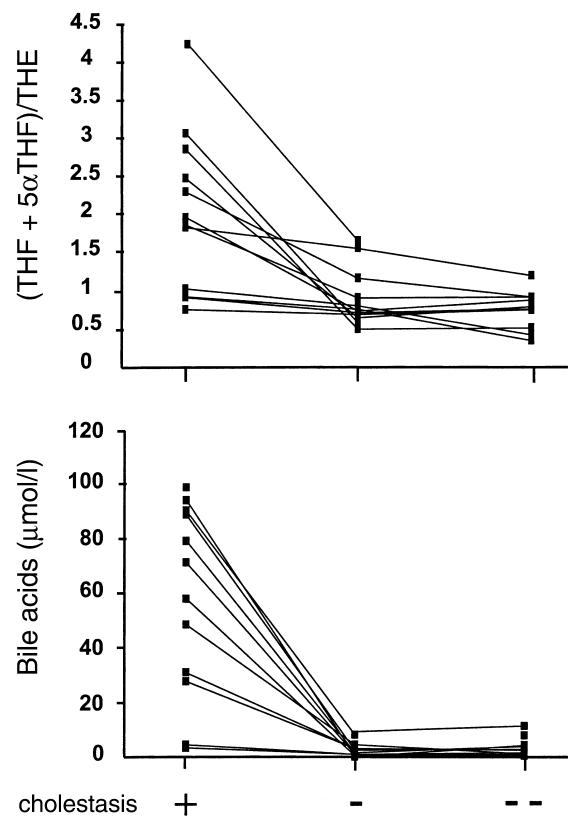

Figure 2

Impact of removal of biliary obstruction on the urinary ratios of (THF $+5 \alpha \mathrm{THF}) / \mathrm{THE}$ (upper panel) and the concentrations of bile acids in plasma (lower panel). Data are given for the time point before biliary obstruction was removed $(+)$ and at the first $(-)$ and second (- ) review after successful therapy. 
Table 2

Parameters in individual patients during cholestasis

\begin{tabular}{|c|c|c|c|c|c|c|c|c|c|c|c|}
\hline \multirow[t]{2}{*}{ Patient } & \multirow[t]{2}{*}{ Etiology } & \multirow{2}{*}{$\begin{array}{c}\text { (THF + } \\
5 \alpha \mathrm{THF}) \\
/ \mathrm{THE}\end{array}$} & \multirow{2}{*}{$\begin{array}{l}\text { Total bile acids } \\
\text { in plasma } \\
(\mu \mathrm{M} / \mathrm{I})\end{array}$} & \multicolumn{3}{|c|}{ CDCA in urine $(\mu \mathrm{M} / \mathrm{I})$} & \multicolumn{3}{|c|}{ CA in urine $(\mu \mathrm{M} / \mathrm{I})$} & \multirow{2}{*}{$\begin{array}{l}\text { Fractional } \\
\text { sodium } \\
\text { excretion }\end{array}$} & \multirow[t]{2}{*}{ Drugs } \\
\hline & & & & total & sulph. & unsulph. & total & sulph. & unsulph. & & \\
\hline K.G. & Choledocholithiasis & 1.02 & 3 & 31 & 24 & 7 & 59 & 41 & 18 & 0.26 & A \\
\hline S.F. & Malformation of bile duct & 2.29 & 31 & 70 & 65 & 5 & 103 & 94 & 9 & - & $B, C$ \\
\hline J.K. & Carcinoma of pancreas & 1.86 & 48 & 43 & 37 & 6 & 12 & 1 & 11 & - & $\mathrm{D}$ \\
\hline S.C. & Choledocholithiasis & 0.92 & 58 & 19 & 14 & 5 & 14 & 2 & 12 & 0.52 & $\mathrm{C}$ \\
\hline H.U. & Choledocholithiasis & 2.47 & 89 & 80 & 74 & 6 & 96 & 85 & 11 & - & $E, F$ \\
\hline G.M. & Choledocholithiasis & 0.76 & 94 & 71 & 64 & 7 & 104 & 90 & 14 & - & $\mathrm{E}, \mathrm{G}$ \\
\hline R.I. & Choledocholithiasis & 1.96 & 79 & 114 & 109 & 5 & 89 & 69 & 20 & - & $\mathrm{E}$ \\
\hline R.O. & Carcinoma of choledochus & 1.83 & 90 & 36 & 31 & 5 & 13 & 7 & 6 & - & $\mathrm{C}, \mathrm{E}$ \\
\hline P.R. & Choledocholithiasis & 2.85 & 99 & 76 & 69 & 7 & 117 & 102 & 15 & - & $\mathrm{H}$ \\
\hline A.K. & Choledocholithiasis & 0.91 & 71 & 149 & 142 & 7 & 141 & 130 & 11 & 0.29 & - \\
\hline F.J. & Choledocholithiasis & 4.26 & 28 & 46 & 41 & 5 & 91 & 67 & 24 & 0.29 & - \\
\hline B.M. & Choledocholithiasis & 3.06 & 5 & 85 & 84 & 1 & 114 & 113 & 1 & 0.37 & A \\
\hline
\end{tabular}

AUrsodeoxycholic acid; Benalapril; Cacetaminophen; Dfurosemide; Ethiazide diuretics; Fquinapril; Gamlodipine; Hindapamide. Sulph., sulphated; Unsulph., unsulphated.

analysis of intracellular distribution of MR, an observer who was blinded to the cell treatment procedures counted the cells under the transmitted light. Cells staining positive for MR were determined and classified into three categories: $\mathrm{C}$, predominantly cytoplasmic; $\mathrm{C} / \mathrm{N}$, cytoplasmic and nuclear; N, predominantly nuclear. Approximately 400 positive cells were analyzed per experiment, and data were obtained from three independent transfection experiments.

Analysis of data. Results are expressed as median and range. Differences between the groups were analyzed by Mann-Whitney $U$ test.

\section{Results}

The biochemical parameters reflecting cholestasis improved in all 12 patients following the removal of biliary obstruction (Table 1). This improvement was evident during both the first and second review. Plasma bile acids, measured by RIA, declined in every patient (Figure 2). After therapy only one patient had bile acid levels approximately $50 \%$ above the upper limit of the normal range $(6 \mu \mathrm{mol} / \mathrm{l})$. The bile acid concentration was not available for one patient at the first review (Figure 2). Bile acid composition was analyzed by gas chromatography-mass spectrometry in urine. The samples obtained after the removal of biliary obstruction contained only negligible concentrations (data not shown), whereas during cholestasis CDCA and CA were present in comparable concentrations (Table 2). In order to analyze the impact of cholestasis on the urinary excretion of electrolytes, patients had to be studied without the intake of cardiovascular medications. Therefore, it was only possible to analyze the fractional renal sodium excretion (FENa) in a subgroup of five patients before and after removal of biliary obstruction. In these patients the FENa increased from $0.29(0.26-0.52)$ during cholestasis to $0.65(0.43-1.76)$ $(P<0.02)$ at the first review.

When cholestasis was corrected, the pattern of urinary cortisol metabolites changed, as shown in Figure 2 and Table 1 . The normal range of urinary (THF +
$5 \alpha \mathrm{THF}) / \mathrm{THE}$ is $0.75-1.25(25,26)$. This ratio was significantly above the normal range during cholestasis in our patients, indicating reduced $11 \beta-\mathrm{HSD} 2$ activity. After removal of the biliary obstruction, the urinary ratio of (THF $+5 \alpha \mathrm{THF}) /$ THE declined in all patients (Figure 2). This decrease of urinary (THF + $5 \alpha \mathrm{THF}$ )/THE was paralleled by a decrease in plasma bile acids. When the urinary cortisol/cortisone ratio (normal range: $0.28-0.85$ ) was analyzed as a measure of $11 \beta$-HSD activity, similar changes were observed: cortisol/cortisone during cholestasis, median 1.29 (range 0.63-2.57); at the first review, median 0.68 (range $0.37-1.51)(P<0.02$ vs. cholestasis); and at the second review, median 0.50 (range $0.27-1.24)(P<0.01$ vs. cholestasis) (Table 3 ). The higher ratios of cortisol/ cortisone and (THF $+5 \alpha \mathrm{THF}) / \mathrm{THE}$ in the patients

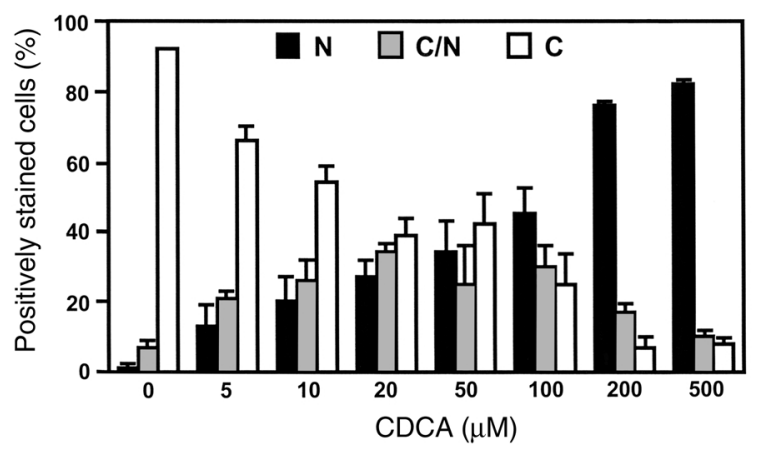

Figure 3

Quantitative analysis of cortisol-induced nuclear translocation of MR after inhibition of $11 \beta-H S D 2$ by CDCA. At 6 hours after cotransfection with MR and $11 \beta-H S D 2$, culture medium was replaced by steroid-free medium and HEK-293 cells were incubated for another 14 hours. Intracellular distribution of MR was analyzed after a 45-minute incubation of cells with $10 \mathrm{nM}$ cortisol in the presence of various concentrations of CDCA. For quantitative analysis, cells staining positive for MR were divided into three categories: $C$, predominantly cytoplasmic, black bars; $\mathrm{C} / \mathrm{N}$, cytoplasmic and nuclear, gray bars; N, predominantly nuclear, white bars. Results are expressed as a percentage of the positive cells and were obtained from three independent transfection experiments. 
Table 3

Cortisol, cortisone concentrations, and cortisol/cortisone ratios in urine during cholestasis and at first and second review

\begin{tabular}{|c|c|c|c|c|c|c|c|c|c|}
\hline \multirow[t]{2}{*}{ Patient } & \multicolumn{3}{|c|}{ Cholestasis } & \multicolumn{3}{|c|}{ First review } & \multicolumn{3}{|c|}{ Second review } \\
\hline & $\begin{array}{l}\text { Cortisol } \\
(\mu \mathrm{g} / \mathrm{ml})\end{array}$ & $\begin{array}{c}\text { Cortisone } \\
(\mu \mathrm{g} / \mathrm{ml})\end{array}$ & $\begin{array}{l}\text { Cortisol/ } \\
\text { Cortisone }\end{array}$ & $\begin{array}{l}\text { Cortisol } \\
(\mu \mathrm{g} / \mathrm{ml})\end{array}$ & $\begin{array}{l}\text { Cortisone } \\
(\mu \mathrm{g} / \mathrm{ml})\end{array}$ & $\begin{array}{l}\text { Cortisol/ } \\
\text { Cortisone }\end{array}$ & $\begin{array}{l}\text { Cortisol } \\
(\mu \mathrm{g} / \mathrm{ml})\end{array}$ & $\begin{array}{c}\text { Cortisone } \\
(\mu \mathrm{g} / \mathrm{ml})\end{array}$ & $\begin{array}{l}\text { Cortisol/ } \\
\text { Cortisone }\end{array}$ \\
\hline K.G. & 0.085 & 0.067 & 1.25 & 0.009 & 0.017 & 0.52 & 0.003 & 0.012 & 0.27 \\
\hline S.F. & 0.438 & 0.351 & 1.25 & 0.096 & 0.098 & 0.98 & 0.019 & 0.059 & 0.33 \\
\hline J.K. & 0.448 & 0.255 & 1.76 & 0.117 & 0.185 & 0.63 & 0.047 & 0.077 & 0.61 \\
\hline S.C. & 0.013 & 0.021 & 0.63 & 0.078 & 0.109 & 0.71 & 0.017 & 0.033 & 0.52 \\
\hline H.U. & 1.007 & 0.758 & 1.33 & 0.038 & 0.083 & 0.46 & 0.011 & 0.025 & 0.42 \\
\hline G.M. & 0.067 & 0.101 & 0.67 & 0.017 & 0.022 & 0.79 & 0.043 & 0.049 & 0.88 \\
\hline R.I. & 0.190 & 0.124 & 1.53 & 0.229 & 0.151 & 1.51 & 0.055 & 0.045 & 1.24 \\
\hline R.O. & 0.034 & 0.073 & 0.46 & 0.040 & 0.061 & 0.65 & 0.017 & 0.047 & 0.37 \\
\hline P.R. & 0.143 & 0.205 & 0.70 & 0.090 & 0.090 & 1.00 & 0.067 & 0.143 & 0.47 \\
\hline A.K. & 1.271 & 0.729 & 1.74 & 0.085 & 0.097 & 0.92 & 0.077 & 0.088 & 0.87 \\
\hline F.J. & 1.375 & 0.805 & 1.71 & 0.067 & 0.145 & 0.37 & - & - & - \\
\hline B.M. & 0.391 & 0.152 & 2.57 & 0.055 & 0.052 & 1.06 & - & - & - \\
\hline Median & 0.290 & 0.178 & 1.29 & 0.073 & 0.094 & 0.68 & 0.045 & 0.054 & 0.50 \\
\hline Range & $0.013-1.375$ & $0.021-0.805$ & $0.63-2.57$ & $0.009-0.229$ & $0.017-0.185$ & $0.37-1.51$ & $0.003-0.077$ & $0.012-0.143$ & $0.27-1.24$ \\
\hline
\end{tabular}

with cholestasis than in the patients without cholestasis were not explained by increased cortisol concentrations in plasma.

In order to investigate the inhibitory effect of CDCA on the protective function of $11 \beta$-HSD2 on MR, we coexpressed epitope-tagged $11 \beta-H S D 2$ and MR in HEK-293 cells and analyzed the intracellular distribution of the MR in the presence of $10 \mathrm{nM}$ cortisol and various concentrations of CDCA (Figure 3 ). Increasing concentrations of CDCA, shown previously to inhibit $11 \beta$-HSD2 activity with a half-maximal inhibitory constant $\left(K_{\mathrm{i}}\right)$ of about $20 \mu \mathrm{M}(19,20)$, led to cortisolinduced nuclear translocation of the MR (Figures 3 and 4). In the absence of CDCA, virtually all of the MR were cytoplasmic, whereas approximately $40 \%$ of MR were nuclear at $50 \mu \mathrm{M}$ CDCA and more than $80 \%$ of $M R$ were nuclear at CDCA concentrations higher than $200 \mu \mathrm{M}$ (Figure 4). Similarly, the presence of CA resulted in cortisol-induced nuclear MR translocation, although this was only evident at concentrations above $200 \mu \mathrm{M}$ (not shown). Aldosterone-dependent nuclear translocation of the MR was not affected by the presence of $10 \mu \mathrm{M}$ CDCA or $100 \mu \mathrm{M}$ CA (not shown). Cortisol-induced MR translocation did not require transfection with $11 \beta-H S D 2$ (8).

\section{Discussion}

The present investigation revealed a mean increase of approximately $100 \%$ in the urinary ratios of (THF + $5 \alpha \mathrm{THF}) / \mathrm{THE}$ and cortisol/cortisone in patients with cholestasis, indicating impaired activity of $11 \beta-H S D 2$. A decrease of this magnitude in the activity of $11 \beta-H S D 2$ confers mineralocorticoid action by cortisol with renal sodium retention and potassium loss, a contention supported by the observation of similar changes in these urinary ratios following the administration of glycyrrhetinic acid, a model compound for $11 \beta-H S D 2$ inhibition $(28,29)$.
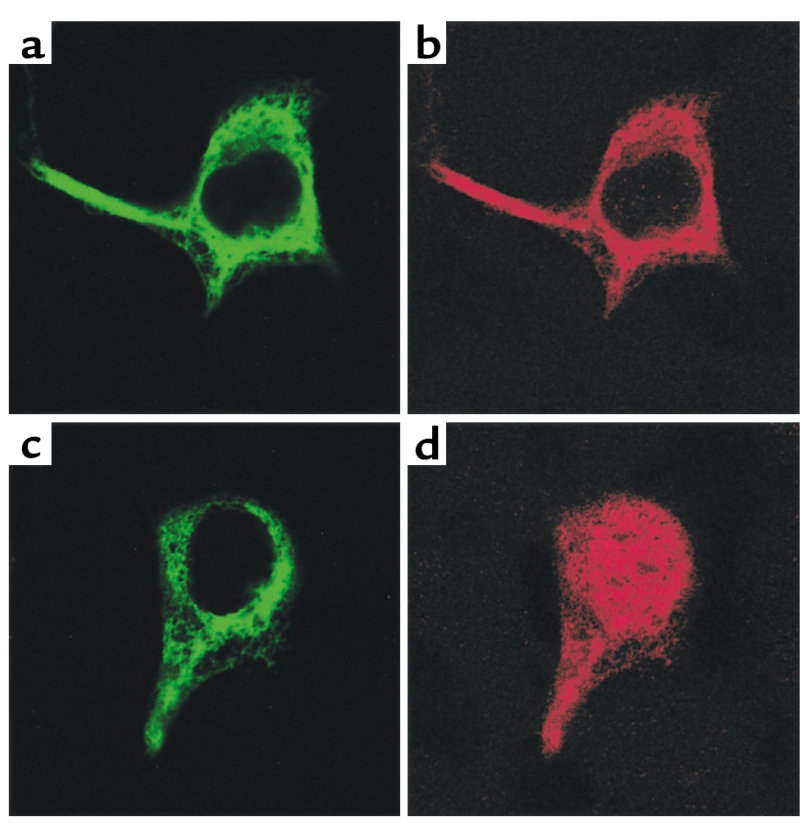

\section{Figure 4}

Cortisol-induced translocation of MR from cytoplasm to nucleus after inhibition of $11 \beta$-HSD2 by CDCA. HEK-293 cells were cotransfected with FLAG-tagged $11 \beta$-HSD2 and HA-tagged MR. Culture medium was replaced by steroid-free medium 6 hours after transfection and cells were incubated for another 14 hours, followed by a 45-minute treatment with $10 \mathrm{nM}$ cortisol either in the absence of CDCA ( $\mathbf{a}$ and $\mathbf{b}$ ) or in the presence of $100 \mu \mathrm{M} \mathrm{CDCA} \mathrm{(c} \mathrm{and} \mathbf{d}$ ). Intracellular localization of $11 \beta-H S D 2$ was analyzed by immunostaining using anti-FLAG antibody and ALEXA-488 antibody ( $\mathbf{a}$ and c). Localization of MR was visualized by using anti-HA antibody and ALEXA-594 antibody (b and d). $\times 400$. In the absence of CDCA, the $M R$ is localized in the cytoplasm and cortisol is unable to induce nuclear translocation (b). In the presence of CDCA, cortisol induces a translocation of the MR from the cytoplasm to the nucleus (d). $11 \beta$-HSD2 remains always anchored to the endoplasmic reticulum membrane and is directed into the cytoplasm (a and $\mathbf{c}$ ). 
The mediators accounting for the reduced $11 \beta$-HSD2 activity in patients with cholestasis are most likely bile acids, as shown by studies performed in vitro and in vivo (19-23). For instance, the kinetics of urinary bile acid excretion after bile duct ligation follow the changes of $11 \beta$-HSD2 activity in rats (19), and in the present investigation a concomitant normalization of impaired $11 \beta$-HSD2 activity and increased urinary bile acid excretion were observed in patients. In line with these observations, we have now demonstrated, using epitope-tagged $11 \beta$-HSD2 and MR coexpressed in HEK-293 cells, that bile acids facilitate access of the glucocorticoid cortisol to the MR. In these cells cortisol was unable to mediate the translocation of the MR from the cytoplasm to the nucleus, because the $11 \beta$-HSD2 enzyme converted cortisol into biologically inactive cortisone. When $11 \beta$-HSD2 was inhibited by CDCA, cortisol caused nuclear translocation of the $\mathrm{MR}$. The CDCA concentration required for half-maximal inhibition of $11 \beta-H S D 2$ in cell lysates $\left(K_{\mathrm{i}}\right.$ approximately $20 \mu \mathrm{M})(20)$ and the CDCA concentration required to mediate $50 \%$ cortisol-induced nuclear MR translocation in intact cells $(50 \mu \mathrm{M})$ are in the same range, indicating efficient access of extracellular CDCA to $11 \beta$-HSD2. Bile acid concentrations have previously been measured in patients with extrahepatic cholestasis and cirrhosis of various etiologies $(30,31)$. The serum concentrations of CDCA were of the same magnitude in patients with extrahepatic cholestasis and patients with cirrhosis and were within the concentration range sufficient to inhibit $11 \beta-H S D 2$. Thus it is reasonable to assume that bile acids abrogate the protective effect of $11 \beta-H S D 2$, allowing uninhibited access of the glucocorticoid cortisol to the MR in both patients with liver cirrhosis and patients with extrahepatic obstruction.

In the present investigation we focused primarily on the action of CDCA to support the hypothesis that bile acids cause cortisol-induced MR activation. CDCA was chosen for the following reasons. Whereas an inhibitory effect on $11 \beta$-HSD2 activity has been shown with many clinically relevant bile acids in vitro or ex vivo (19, 20 ), the mineralocorticoid effect in vivo has only been demonstrated with CDCA in an acute experiment in rats (23). In contrast to CDCA, CA conferred virtually no mineralocorticoid activity (23). The latter observation in rats is in line with the weak activity of CA in our MR translocation assay. CDCA accounts for approximately $50 \%$ of the bile acids excreted in urine, either in native or in conjugated form (Table 2) (30). The concentrations of CDCA found in urine of patients with cholestasis are of the same magnitude as those required to inhibit recombinant human $11 \beta$-HSD2 in cell extracts or rat $11 \beta$-HSD2 in microdissected cortical collecting ducts $(19,20)$. Whether similar concentrations of CDCA are found in the cortical collecting ducts of patients with cholestasis is unknown. The cortical collecting duct is at the end of the nephron, and it is reasonable to assume that the concentrations of CDCA observed in urine are close to those found in this part of the nephron. Barany analyzed bile acid uptake in kidney tissue in 1975 and observed a tissue-to-medium ratio of 37 for CDCA and 16 for CA, indicating accumulation of those bile acids with a preference for CDCA (32). No simple linear relationship between the decline in the 11ß-HSD2 activity (assessed by measuring glucocorticoid metabolites in urine) and the concentrations of an individual bile acid was demonstrated in the present investigation in patients. However, this is not surprising, given the various bile acids, either conjugated or nonconjugated, present in cholestasis, the differential renal handling of these steroids, and their individual potency for inhibition of $11 \beta$-HSD2.

There is a consensus that renal sodium retention and potassium loss occur in cirrhosis, but opinions differ with respect to temporal relationship, mechanism, and relevance of aldosterone $(13-18,33,34)$. The enhanced activation of MR by cortisol in the presence of bile acids might reconcile some of the different observations with respect to sodium retention in cirrhosis. The observation that cortisol acts as a mineralocorticoid indicates that aldosterone is not the only endobiotic able to enhance renal tubular sodium retention and potassium excretion in patients with cholestasis. Bile acids confer cortisol-induced activation of MR and, therefore, account at least in part for the cross-talk between liver and kidney in disease states with increased bile acid concentrations such as liver cirrhosis. Bile acid concentrations increase many-fold during the initial hours after biliary obstruction in urine and thus promote aldosterone-independent renal sodium retention and potassium loss without prior renal hypoperfusion due to intra-abdominal fluid sequestration.

In conclusion, the activity of $11 \beta$-HSD 2 and the consequent renal conversion of cortisol to cortisone are reduced in cholestasis. Such an impaired conversion allows access of cortisol to MR, thus resulting in aldosterone-independent renal sodium retention and potassium loss.

\section{Acknowledgments}

We gratefully acknowledge the critical comments of J. Reichen. This work was supported by three grants from the Swiss National Foundation for Scientific Research (Nr 32-57205.99, $\mathrm{Nr} 31-061505.00$, and Nr 31-59511.99).

1. Funder, J.W., Pearce, P.T., Smith, R., and Smith, A.I. 1988. Mineralocorticoid action: target tissue specificity is enzyme, not receptor, mediated. Science. 242:583-585.

2. Edwards, C.R., et al. 1988. Localisation of 11ß-hydroxysteroid dehydrogenase-tissue specific protector of the mineralocorticoid receptor. Lancet. 2:986-989.

3. Stewart, P.M., and Whorwood, C.B. 1994. 11ß-Hydroxysteroid dehydrogenase activity and corticosteroid hormone action. Steroids. 59:90-95.

4. Escher, G., Galli, I., Vishwanath, B.S., Frey, B.M., and Frey, F.J. 1997. Tumor necrosis factor $\alpha$ and interleukin $1 \beta$ enhance the cortisone/cortisol shuttle. J. Exp. Med. 186:189-198.

5. Albiston, A.L., Obeyesekere, V.R., Smith, R.E., and Krozowski, Z.S. 1994. Cloning and tissue distribution of the human $11 \beta$-hydroxysteroid dehydrogenase type 2 enzyme. Mol. Cell. Endocrinol. 105:R11-R17.

6. Odermatt, A., Arnold, P., Stauffer, A., Frey, B.M., and Frey, F.J. 1999. The $\mathrm{N}$-terminal anchor sequences of $11 \beta$-hydroxysteroid dehydrogenases determine their orientation in the endoplasmic reticulum membrane. J. 
Biol. Chem. 274:28762-28770.

7. Bostanjoglo, M., et al. 1998. 11ß-hydroxysteroid dehydrogenase, mineralocorticoid receptor, and thiazide-sensitive $\mathrm{Na}-\mathrm{Cl}$ cotransporter expression by distal tubules. J. Am. Soc. Nephrol. 9:1347-1358.

8. Odermatt, A., Arnold, P., and Frey, F.J. 2001. The intracellular localization of the mineralocorticoid receptor is regulated by $11 \beta$-hydroxysteroid dehydrogenase type 2. J. Biol. Chem. 276:28484-28492.

9. Biller, K.J., Unwin, R.J., and Shirley, D.G. 2001. Distal tubular electrolyte transport during inhibition of renal $11 \beta$-hydroxysteroid dehydrogenase. Am. J. Physiol. Renal Physiol. 280:F172-F179.

10. Arriza, J.L., et al. 1987. Cloning of human mineralocorticoid receptor complementary DNA: structural and functional kinship with the glucocorticoid receptor. Science. 237:268-275.

11. Dave-Sharma, S., et al. 1998. Examination of genotype and phenotype relationships in 14 patients with apparent mineralocorticoid excess. $J$. Clin. Endocrinol. Metab. 83:2244-2254.

12. Kotelevtsev, Y., et al. 1999. Hypertension in mice lacking $11 \beta$-hydroxysteroid dehydrogenase type 2. J. Clin. Invest. 103:683-689.

13. Schrier, R.W. 1988. Pathogenesis of sodium and water retention in highoutput and low-output cardiac failure, nephrotic syndrome, cirrhosis, and pregnancy. N. Engl. J. Med. 319:1127-1134.

14. Levy, M., and Wexler, M.J. 1978. Renal sodium retention and ascites formation in dogs with experimental cirrhosis but without portal hypertension or increased splanchnic vascular capacity. J. Lab. Clin. Med. 91:520-536.

15. Levy, M., and Allotey, J.B. 1978. Temporal relationships between urinary salt retention and altered systemic hemodynamics in dogs with experimental cirrhosis. J. Lab. Clin. Med. 92:560-569.

16. Wensing, G., Sabra, R., and Branch, R.A. 1990. The onset of sodium retention in experimental cirrhosis in rats is related to a critical threshold of liver function. Hepatology. 11:779-786.

17. Jimenez, W., et al. 1985. Temporal relationship between hyperaldosteronism, sodium retention and ascites formation in rats with experimental cirrhosis. Hepatology. 5:245-250.

18. Bernardi, M., et al. 1993. Renal sodium retention during upright posture in preascitic cirrhosis. Gastroenterology. 105:188-193.

19. Ackermann, D., et al. 1999. Inhibition of $11 \beta$-hydroxysteroid dehydrogenase by bile acids in rats with cirrhosis. Hepatology. 30:623-629.

20. Escher, G., et al. 1998. Down-regulation of hepatic and renal $11 \beta$-hydroxysteroid dehydrogenase in rats with liver cirrhosis. Gastroenterology. 114:175-184.
21. Perschel, F.H., Buhler, H., and Hierholzer, K. 1991. Bile acids and their amidates inhibit $11 \beta$-hydroxysteroid dehydrogenase obtained from rat kidney. Pflugers Arch. 418:538-543.

22. Morris, D.J., and Souness, G.W. 1996. Endogenous 11ß-hydroxysteroid dehydrogenase inhibitors and their role in glucocorticoid $\mathrm{Na}^{+}$retention and hypertension. Endocr. Res. 22:793-801.

23. Latif, S.A., Hartman, L.R., Souness, G.W., and Morris, D.J. 1994. Possible endogenous regulators of steroid inactivating enzymes and glucocorticoid-induced $\mathrm{Na}^{+}$retention. Steroids. 59:352-356.

24. Riddle, M.C., and McDaniel, P.A. 1994. Renal 11ß-hydroxysteroid dehydrogenase activity is enhanced by ramipril and captopril. J. Clin. Endocrinol. Metab. 78:830-834.

25. Shackleton, C.H. 1986. Profiling steroid hormones and urinary steroids. J. Chromatogr. 379:91-156.

26. Vogt, B., Dick, B., N'Gankam, V., Frey, F.J., and Frey, B.M. 1999. Reduced $11 \beta$-hydroxysteroid dehydrogenase activity in patients with the nephrotic syndrome. J. Clin. Endocrinol. Metab. 84:811-814.

27. Shackleton, C.H.L., Merdinck, J., and Lawson, A.M. 1990. Steroid and bile acid analysis. In Mass spectrometry of biological materials. C.N. McEwen and B.S. Larsen, editors. Marcel Dekker Inc. New York, New York, USA 297-377.

28. Stewart, P.M., et al. 1987. Mineralocorticoid activity of liquorice: $11 \beta$-hydroxysteroid dehydrogenase deficiency comes of age. Lancet. 2:821-824.

29. Ferrari, P., Sansonnens, A., Dick, B., and Frey, F.J. 2001. In vivo $11 \beta$ HSD-2 activity: variability, salt-sensitivity, and effect of licorice. Hypertension. 38:1-7.

30. van Berge Henegouwen, G.P., Brandt, K.H., Eyssen, H., and Parmentier, G. 1976. Sulphated and unsulphated bile acids in serum, bile, and urine of patients with cholestasis. Gut. 17:861-869.

31. Pennington, C.R., Ross, P.E., and Bouchier, I.A. 1977. Serum bile acids in the diagnosis of hepatobiliary disease. Gut. 18:903-908.

32. Barany, E.H. 1975. In vitro uptake of bile acids by choroid plexus, kidney cortex and anterior uvea. I. The iodipamide-sensitive transport systems in the rabbit. Acta Physiol. Scand. 93:250-268.

33. Wood, L.J., Massie, D., McLean, A.J., and Dudley, F.J. 1988. Renal sodium retention in cirrhosis: tubular site and relation to hepatic dysfunction. Hepatology. 8:831-836.

34. Wong, F., Liu, P., Allidina, Y., and Blendis, L. 1995. Pattern of sodium handling and its consequences in patients with preascitic cirrhosis. Gastroenterology. 108:1820-1827. 